\title{
Modelling the Impact of Mobile Application Adoption on the Taxi Demand: An Application of a System Dynamics Approach
}

\author{
https://doi.org/10.3991/ijim.v15i06.20633 \\ Muhamad Syafiq Abdul Ghani $\left({ }^{\varpi}\right)$, Norhaslinda Zainal Abidin \\ Rosshairy Abd Rahman \\ Universiti Utara Malaysia, Kedah, Malaysia \\ abdulghani4567@yandex.com \\ Antoni Wibowo \\ Bina Nusantara University, Jakarta, Indonesia \\ Azatuliffah Alwi \\ Universiti Utara Malaysia, Kedah, Malaysia
}

\begin{abstract}
The improvement of technology brings a significant impact on transportation industries. The taxi industry has undergone tremendous changes with the existent of e-hailing service in the industry. Due to the introduction of mobile applications, e-hailing service takes part to compete in the market. The government has given priority to overcome the problem by introducing travel demand strategies that focus on mitigating the demand competition between the taxi and e-hailing services. One of the strategies is the adoption of a mobile application in taxi service. This paper aims to develop a system dynamics model to analyse mobile application adoption's impact on customers' demand on the mode share of taxi and e-hailing services as a measured output. System dynamics is a decision-experimentation method that creates a learning environment in which policymakers gain a better understanding of how the system will respond to their decisions and the potential unintended consequences of decisions. With the developed SD model, the feedback relations between mobile application adoptions on the output of taxi demand can be observed. Furthermore, the demand competition between the taxi and e-hailing services can be minimised using this SD model. The result shows that, by implementing the usage of the mobile application in taxi services, more users will be attracted to use the taxi service. With that service option, users will shift their attraction from e-hailing to taxi service, which is then able to minimise the demand competition. This research can benefit policymakers and authorities in the department of transportation to serve as a planning tool so that the demand of taxi and e-hailing services in Malaysia with the adoption of mobile application in taxi service can be predicted.
\end{abstract}

Keywords - Taxi service, E-hailing service, System Dynamics, Mobile Application, Mode share 


\section{Introduction}

Tremendous changes in the taxi industry over the world, including Malaysia, occurred due to the evolution era and the emergence of mobile transportation app-based [1]. Traditionally, the taxi driver received an order from the customer by hailing on the street or booking through phone calls. However, with the improvement in technology, e-hailing services take part in the market by offering a mobile application for taxi services request.

E-hailing application is a platform that enables online booking and dispatch of available e-hailing drivers located in the proximity area of the users [2]. This application is supported with the location identification, taxi booking, payment, and communication system between the driver and customer. The adoption of e-hailing service offers a customer with a variety of choices in having a mode for their transportation service.

Currently, e-hailing service received an overwhelming welcome by the customer with the increasing demand from them. This situation negatively impacts the traditional taxi service as demand competition between both services became a serious issue in the Malaysian public transport industry. A number of studies have been conducted to identify the customers' preference factors towards e-hailing services. The findings show that fare and accessibility are the most significant factors for a customer to book an e-hailing service [3-5]. With the mobile application adoption issue, this study aims to develop a system dynamics model to analyse the impact of the mobile application adoption in taxi service towards the demand of customers. Many studies have been found in the literature that used system dynamics model in the transportation system [68]. However, based on the researcher knowledge, there is no application found that focuses on mitigating competition demands between the taxi and e-hailing services, especially in Malaysia.

The rest of this paper is organised as follows: The next section reviews the studies on the customers' preference factors towards taxi and e-hailing usage. It is followed by the review of studies on application system dynamics focusing on the transportation domain. The next section presents the methodology used in this research focusing on the modelling process. The following section presents the proposed framework to explain the causal relationship between the demand for taxi and e-hailing services. Finally, the conclusion and future works are explained in the last section.

\section{Literature Review}

\subsection{Customers' preference factors}

Travel cost: Fare is one of the important factors on customers' affordability in choosing the mode share of transportation [9]. A study by Balachandran and Hamzah [1] found that price is the factor contributing to the customers' satisfaction in choosing their mode share of transportation. Besides, Hashim and Isa [10], highlighted that tangible, responsiveness and price are the factors which influenced the customers' 
satisfaction in choosing taxi services in Kuantan, Pahang. Finally, Qian and Ukhusuri [11] stated that pricing is an important factor in determining between the taxi and ehailing services for their transportation mode. It is known that the majority of the customers who opt for the taxi service are students and lower-income earner, who prefers a cheaper charge of fee transport [12]. In practice, a higher charge of fare will increase travel costs, causing the customer not to choose the service.

Accessibility: In the transportation area, accessibility refers to the quality measure of the easiness in reaching public transport in some places or regions [13]. The important role in the accessibility of public transport assessment is to provide door-todoor mobility with better connectivity of people to their destination. Having good accessibility will ensure public transport to be fully utilised which will ultimately reduce the congestion index [14]. According to Han, Li, Wei, and Zhang [15], the mode share of public transport will be more effective by ensuring better accessibility. The important factors of customers' selection of public transport are accessibility distance, travel time, and transit time [16].

In Malaysia, accessibility is among the main reason why customers prefer using ehailing than the traditional service [4]. E-hailing service is easy to access since it operates through the mobile application. Among the reason why customers prefer to choose e-hailing are: (1) ease of payment and communication, (2) less waiting time, and (3) higher accessibility [2]. Having all these advantages, the use of phones or electronic applications like a taxi booking system will help to increase the demand for taxi service.

\subsection{System dynamics studies related to transportation issues}

Nowadays, many researchers have shown an interest in using system dynamics (SD) in the transportation domain study. SD is an applicable approach that captures a dynamic, non-linear and causal effect of variables in a complex system [17]. Besides, highlighting the system behaviour in the long term with the feedback behaviour impact in a dynamic way is one of the features in SD [18]. With these advantages, SD can be useful in transportation study for policy analysing and design. An example on the use of SD in transportation research is studied by Yevdokimov [6], which focus on the economic, social, and environmental sectors as a dimension for sustainable transportation. This study concluded that mathematical modelling based on aggregating the criteria for sustainability, systematic analysis, and SD is the best combination method to model sustainable transportation systems. These methods addressed all aspects of transportation sustainability simultaneously. Another study by Yang, Zhang, and $\mathrm{Ni}$ [7] conducted a study on the impact of urban rail transit on the metropolitan regions focusing on the urban traffic, economy, society, and environment aspects. In this study, the SD model was developed to simulate the medium- and long-term effects of urban transport policies. Finding from this study was supported by Raux [8] that highlighted an increase in the car ownership would cause to the rise in car trip and congestion index in the long run [23].

The most relevant studies carried out by Nurdden, Rahmat, and Ismail [19], Karim [20] and Wang et al. [21] model the behaviour change of travellers that focus on the 
shifting of mode share. All studies focus on the impact of policies on the sustainability of public transportation services. For instance, Nurdden, Rahmat, and Ismail [19] developed an SD model to study the effect of transportation policies on modal shift issues from private car to public transport in Malaysia. This study has been referenced by Karim [20] that imitate the existing model structure by adding the other related variables, with a hybrid SD method. Karim [20] modified the Nurdden, Rahmat, and Ismail [19]'s model to shift on the use of a private car to public transport. Karim's study developed integration of SD and genetic algorithm model to find the best combination of parameters to achieve the minimum value of congestion index. Finally, a study by Wang et al. [21], developed an SD model for urban taxi management which focus on the impact of taxi fare on the driver's income and travel demand.

Based on the reviewed studies, it can be concluded that SD is suitable to be used to simulate the medium and long-run effect of varies transportation policies considering the influenced factors as a feedback interrelationship that work as a holistic model which changes cause to a chosen policy variable will effect on the other variable [24].

\section{$3 \quad$ Methodology}

In this paper, system dynamics (SD) which is a simulation approach was used to model the changes in the mode share behaviour over time. SD has the capability to capture a dynamic, non-linear, and causal effect of related variables in a transportation complex system. The discussion on the methodology section is divided into modelling process and development of causal loop diagram. The explanations are as follows:

\subsection{Modelling process}

The modelling process of SD methodology involved six keys steps as presented in Figure 1. The steps are problem articulation, data collection, development of causal loop diagram, formulation of stock and flow diagram, model validation, and model evaluation.

As shown in Figure 1, the first stage started with the problem definition and variable identification. The model aims to stimulate the long-term effect of travel demand strategies to address the gaps in the demand between the taxi and e-hailing services. In this paper, two interconnecting components; travel demand and mode share, are shown in Figure 2. These components are highlighted as they set the boundary of the research. This study used secondary data to accomplish the evaluation. The data was taken from a various report published by many government agencies, taxis, and e-hailing companies. For example, the data collected from the Land Public Transport Commission (APAD), Kuala Lumpur City Hall (DBKL), and Grab Malaysia as presented in Table 1. 
Paper-Modelling the Impact of Mobile Application Adoption on the Taxi Demand: An Application...

Table 1. Information of data used in the model

\begin{tabular}{|l|l|l|l|}
\hline \multicolumn{1}{|c|}{ Components } & \multicolumn{1}{|c|}{ Variables } & Duration & \multicolumn{1}{c|}{ Sources } \\
\hline Supply & Number of taxi driver & $2017-2020$ & Agensi Pengangkutan Awam Darat (2019) \\
\hline Mode Share & Number of taxi user & $2017-2020$ & Agensi Pengangkutan Awam Darat (2020) \\
\hline Coverage Area & City area & $2019-2020$ & Dewan Bandaraya Kuala Lumpur (2020) \\
\hline & Average taxi fare per KM & $2017-2020$ & Agensi Pengangkutan Awam Darat (2020) \\
\hline
\end{tabular}

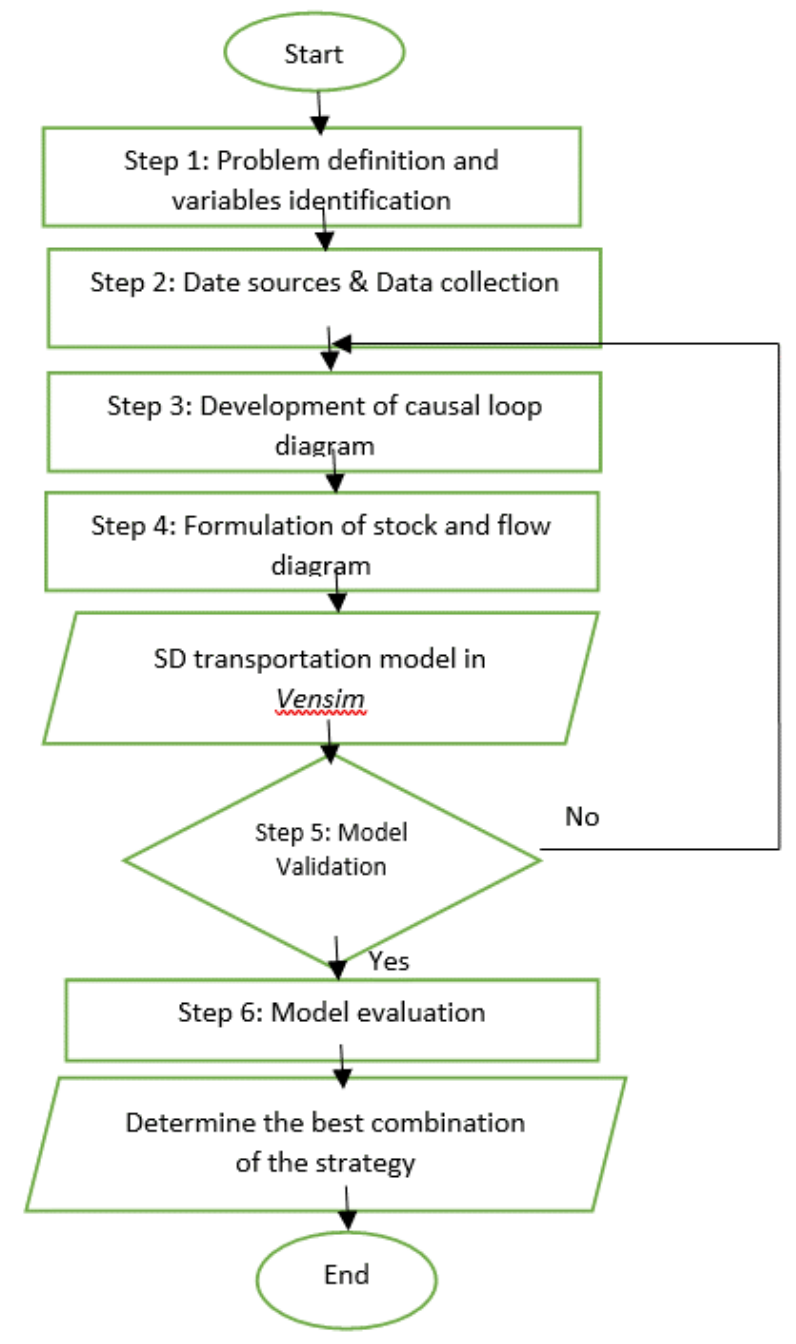

Fig. 1. System dynamics modelling process 

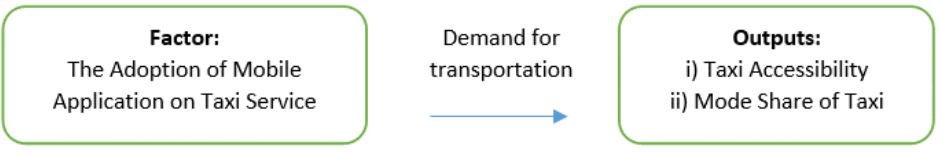

Fig. 2. Boundary of the transportation model

\subsection{Development of causal loop diagram}

The next stage is the development of causal loop diagram (CLD) using an SD software named as Vensim ${ }^{T M}$. CLD is a causal diagram to highlight the interaction of the selected variables and the strategies in the transportation system. CLD is the first step in the SD model that helps to quantitatively analyse the structure of a complex system in terms of cause and effect [22]. CLD connects the causal variables by using arrows to highlight the relationship between variables, while the polarity sign shows the direction of influence. Positive polarity means with the increasing value in one of the variables, the value of another variable will also increase and vice versa. Meanwhile, negative polarity explains the negative relationship between the variables. Increasing the value of the variable will decrease the value for the opposite variable and vice versa. The example of the positive polarity of cause and effect can be referred to in Figure 3. This figure shows with an increase in the toll charge variable, the travel cost per trip for the customer also will increase.

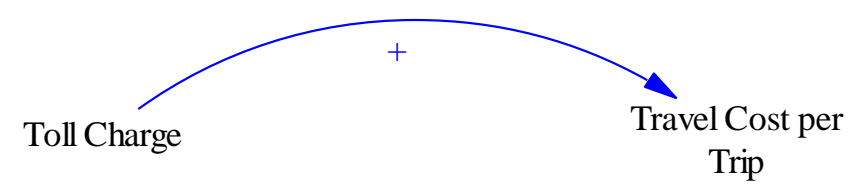

Fig. 3. Example of cause and effect with positive polarity

The overall SD model is organised into four strategies which focus on accessibility and travel cost. The strategies are: (1) Adopting a mobile application for all taxi services, (2) Introducing the application license for e-hailing companies and drivers, (3) Setting a minimum fare for e-hailing services, and (4) Lowering toll charges for traditional taxi services. The overview of the CLD system that shows the feedback caused by the interrelations of these four strategies are presented in Figure 4. 


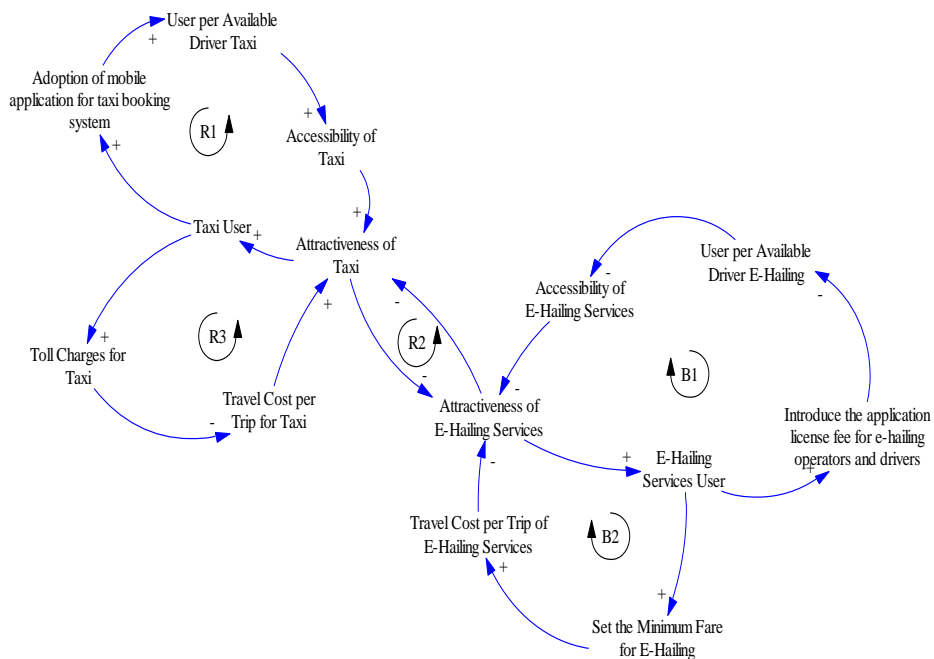

Fig. 4. Causal loop diagram of travel demand strategies for taxi and e-hailing services models

The explanations for each of the balancing (B) and reinforcing (R) loops are as follows:

a) Loop R1: attractiveness of taxi and e-hailing services: Loop R1 is a reinforcing loop which highlighted the interaction between attractiveness of taxi and e-hailing services. Attractiveness of taxi and e-hailing was competed which targeted to attract more demand from the customer. The attractiveness of taxi has a negative relationship with e-hailing services. Increase in the attractiveness of taxi will decrease the attractiveness of e-hailing services and vice versa.

b) Loop R2: adopting a mobile application for all taxi services: Loop R2 shows the proposed strategy to adopt a mobile application for taxi booking system. The usage of the mobile application will bring a positive impact on the accessibility of the taxi service. This is because the customers tend to use a mobile application to request for a taxi service. This situation is shown by reinforcing loop R2, which explained that the increase in the usage of the mobile application for booking system by the taxi driver would increase the accessibility of taxi. Finally, this intervention will increase the attractiveness of the taxi service.

c) Loop B1: introducing the application license for e-hailing companies and drivers: One of the travel demand strategy proposed by the government is to legalise the driver and e-hailing company by introducing a new Business Mediation License (LPP) for e-hailing operator and PSV license for the driver. By introducing this new license, the cost for the driver application and e-hailing companies will be increased. With this strict requirement, the number of the driver in the market will be reduced. This relationship is shown in Loop B1 in Figure 4. This balancing loop explains that the introduction of the applicable license for e-hailing companies and drivers will 
reduce the number of e-hailing drivers in the market. Therefore, accessibility and attractiveness of e-hailing will be reduced at the same time.

d) Loop B2: setting a higher minimum fare for e-hailing service: One of the main components that influences the attractiveness of the public transportation is the price of the fare. Based on the market price, fare for e-hailing service is lower compared to the traditional taxi. The government set a higher fare for e-hailing services to ensure both services are more competitive in terms of prices. Referring to Loop B2, an increase in the minimum fare for e-hailing will increase the travel cost for the customer who are using this service. With the rise in the travel cost for e-hailing, the attractiveness of e-hailing service will be reduced too. The implementation of this strategy will help to increase the attractiveness of the taxi service.

e) Loop B3: lowering the toll charges for traditional taxi service: The toll charge is one of the additional costs that will impact the customers' travel cost. In Malaysia, traditional taxi service has advantages over e-hailing service such as a lower highway toll charge for the taxi compared to e-hailing. By lowering the toll charge for the taxi service, it will help to reduce the total fare for taxi service. This will indirectly attract more passengers to use the service due to the competitive fare. This relationship is explained in Figure 4.

\section{$4 \quad$ Result and Analysis}

\subsection{Validation of model}

One of the tests used to validate the model is dimensional consistency. Dimensional consistency is a test to check whether the right and left sides of the equation in the model are balanced. Using Vensim ${ }^{T M}$, the button function for unit checking was available in the software. All equations in the model have passed the dimensional consistency test by showing the 'OK' message (see Figure 5) in the box.

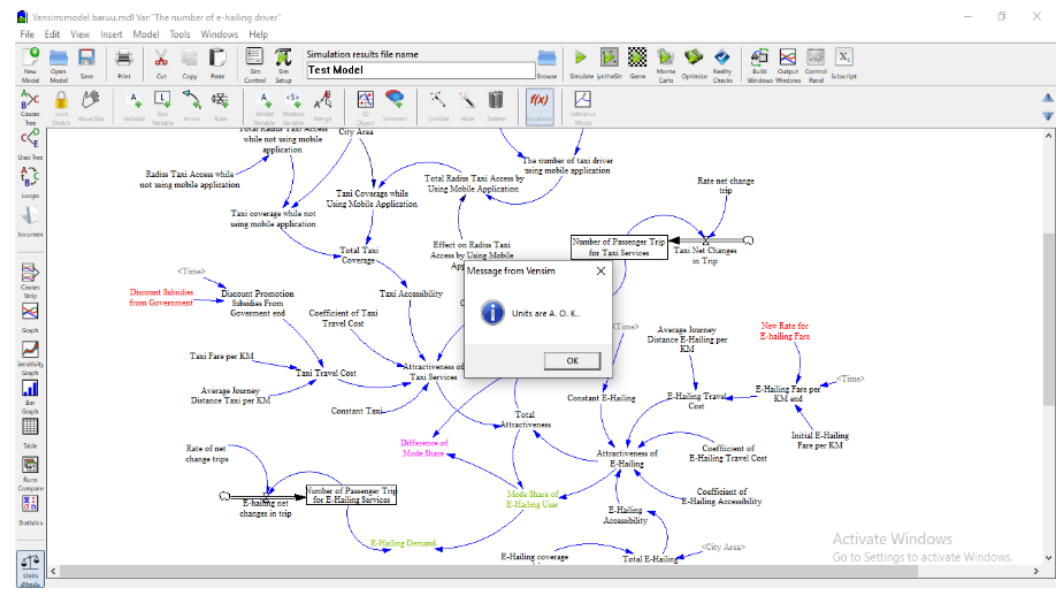

Fig. 5. The model has passed the dimensional consistency test 


\subsection{Base run scenario}

The model is simulated to observe the behaviour trend of demand for taxi and ehailing services in their mode share gaps. The simulation model is run for 30 years, starting from 2010 until the projection year of 2040. The result of the base run scenario is presented in Figure 6. Referring to the figure, the behaviour trend for the mode share for taxi service in the year 2040 will be decreased at a gradual rate. Therefore, the gap for mode share for both taxi and e-hailing services becomes huge, making the taxi market not competitive. With that, the e-hailing service will monopoly the market. For the intervention strategy, the government may need to plan more aggressive strategies towards achieving the close gap of mode share between both services. The strategy must focus on increasing the attractiveness of the taxi service.

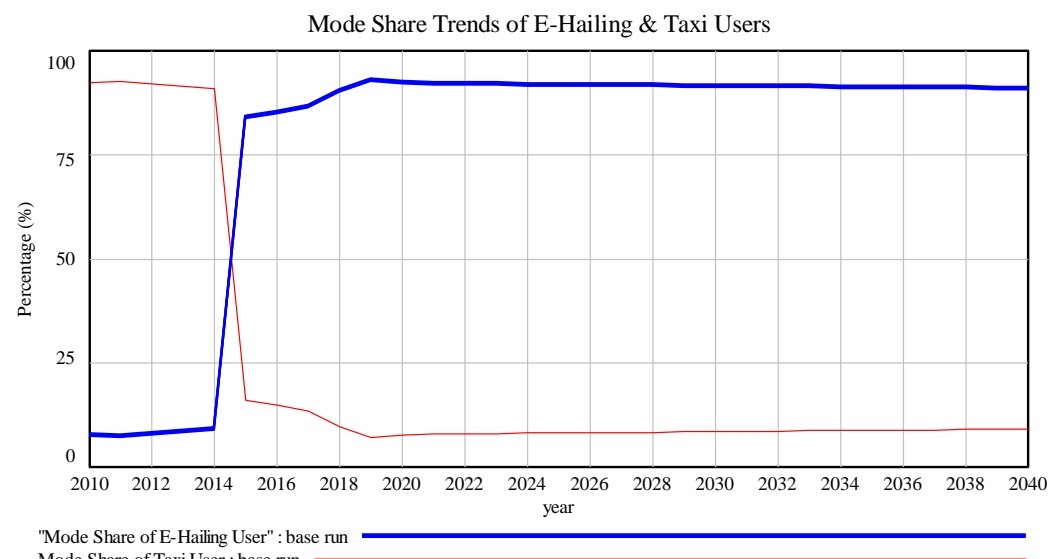

Mode Share of Taxi User : base run

Fig. 6. Comparison of mode share in base run trends

\subsection{Discussion on intervention}

The sensitivity analyses for travel demand strategies are based on the four implemented strategies. However, this study only focuses on implementing one of the strategies named the adoption of a mobile application for the taxi service.

Figure 7, until Figure 9 shows the result of intervention when the mobile application adoption experimented for taxi and e-hailing services. The graph in Figure 7 shows that when all the taxi services utilise the mobile application starting in 2020, this strategy will increase the taxi accessibility. The comparison of taxi users' mode share trends when $25 \%, 50 \%, 75 \%$, and $100 \%$ intervention were analysed. The taxi service's mode share trend is increased when taxi users starts to adopt the mobile application in their services. Our result is supported by the study done by [1], which highlighted that ehailing application have direct and indirect advantages to the taxi driver, such as increasing their income and create a better relationship with passengers. 


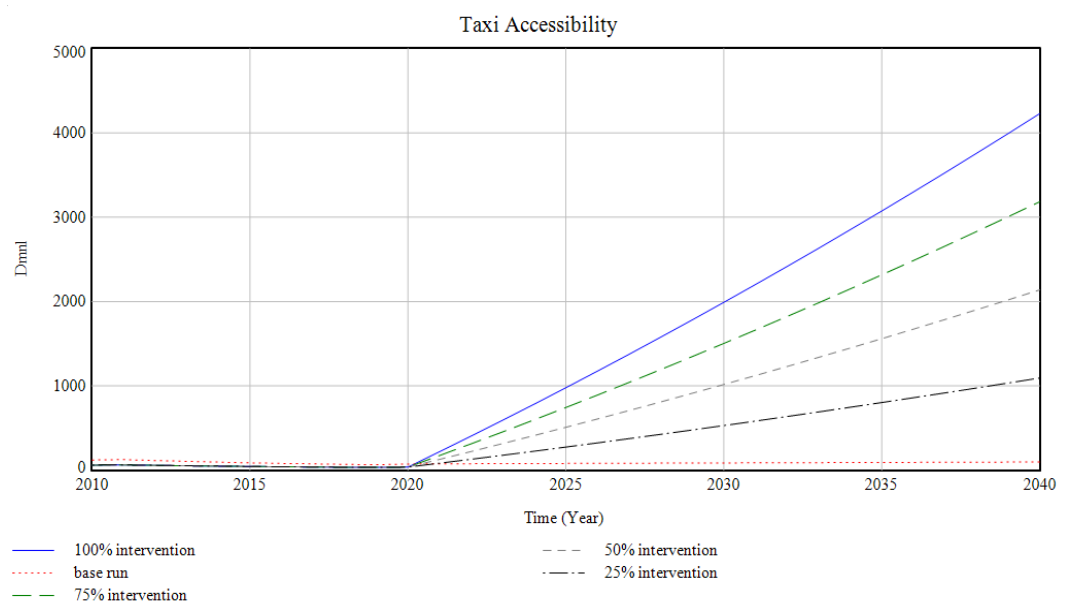

Fig. 7. The trends of intervention for taxi accessibility

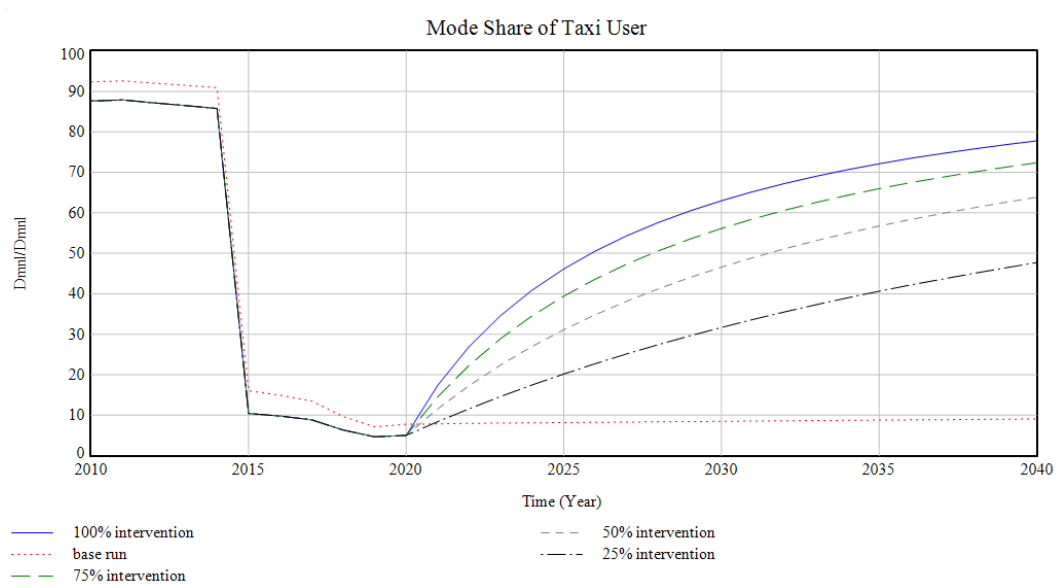

Fig. 8. The comparison of intervention trends for mode share of taxi user

Figure 9 shows that the trend of mode share gap in between taxi and e-hailing services was slowly reduced every year. In the year 2026, the mode share for both services intersect, where both are occurring at a $50 \%$ percentage point. It is found that after the year 2026, the trend for mode share of taxi service is greater than the e-hailing service. 


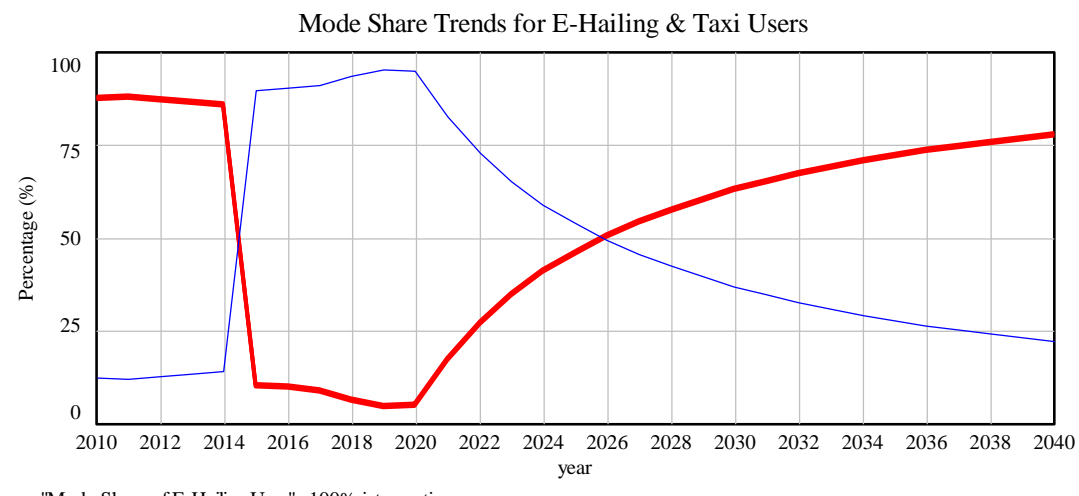

"Mode Share of E-Hailing User" : 100\% intervention

Mode Share of Taxi User : $100 \%$ intervention

Fig. 9. The comparison trends of mode share for taxi users

\section{$5 \quad$ Conclusion and Future Works}

This study attempted to examine the impact of mobile application adoption in taxi service on the customers' demand in reference to mode share of taxi and e-hailing services. This paper adopted the SD method to model a holistic transportation system that consists of the attractiveness of both services, adopting a mobile application for all taxi services, the fare for e-hailing service, and toll charges for traditional taxi service. The result of this study reveals that the adoption of the mobile application is a useful strategy to increase taxi accessibility as customers prefer using e-hailing than taxi service. One of the limitations of this SD model is to search for an optimal value that gives a minimal difference in the demand between the taxi and e-hailing services. Thus, this study's future work will involve testing another travel demand strategy variable named as setting a minimum fare for e-hailing service and lowering a toll charge for traditional taxi service to analyse its impact on the usage of both taxi and e-hailing services. This testing will be involved by using an optimisation method of analysis, namely the Genetic Algorithm. It is a heuristic search that is commonly used to generate high-quality solutions to optimisation problems by relying on biologically inspired operators such as mutation, crossover, and selection.

\section{Acknowledgement}

We would like to express our gratitude to the Ministry of Education Malaysia and Universiti Utara Malaysia through Research and Innovation Management Centre (RIMC) for the grant under Fundamental Research Grant Scheme (FRGS) number 14224 . 


\section{$7 \quad$ References}

[1] Balachandran, I., \& Hamzah, I. B. (2017). The Influence of Customer Satisfaction of Ride-sharing Services in Malaysia. International Journal of Accounting and Business Management. 5(2): 184-196.

[2] Onyango, J. (2016). E-hailing applications adoption and competitiveness of Appbased taxi operators in Nairobi, Kenya. Unpublished MBA project. Nairobi: University of Nairobi. https://doi.org/10.18697/ajfand.84.blfb1017

[3] Sam, E. F., Adu-boahen, K., \& Kissah-korsah, K. (2014). Assessing the factors that influence public transport mode preference and patronage: Perspectives of students of University of Cape Coast ( UCC ), Ghana. 3(2): 323-336.

[4] Premananthini, C. (2016, April 26). A Staggering 80 Percent of the Public Prefer Using Uber, GrabCar Than Cabs, Says SPAD. New Straits Times. Retrieved January 6, 2020, from https://www.nst.com.my/ news/2016/04/141740/staggering-80-centpublic-prefer-using-uber-grabcar-cabs-says-spad

[5] Shoja Rani, B. N. (2018) Socio-economic Analysis of Uber Taxi Driver in Kerala-A Study with Special Reference to Ernakulam District

[6] Yevdokimov, Y. V. (2002). Sustainable transportation system: a system dynamics approach. In 3rd International Conference on Public Economics, Paris.

[7] Yang, Y., Zhang, P., \& Ni, S. (2014). Assessment of the impacts of urban rail transit on metropolitan regions using system dynamics model. Transportation Research Procedia. 4: 521-534. https://doi.org/10.1016/j.trpro.2014.11.040

[8] Raux, C. (2003). A systems dynamics model for the urban travel system.

[9] Button, K. J., \& Hensher, D. A. (2001). Transportation systems. Handbook of Transportation Systems and Traffic Control. 3(1): 33-110.

[10] Hashim, R., \& Isa, M. F. M. (2018). Pengaruh Kualiti Perkhidmatan Teksi Terhadap Kepuasan Pengguna di Kuantan. Politeknik \& Kolej Komuniti Journal of Life Long Learning. 2(1): 106-119.

[11] Qian, X., \& Ukkusuri, S. V. (2017). Taxi market equilibrium with third-party hailing service. Transportation Research Part B: Methodological. 100: 43-63. https://doi.org/10.1016/j.trb.2017.01.012

[12] Veloso, M., Phithakkitnukoon, S., \& Bento, C. (2011). Sensing urban mobility with taxi flow. In Proceedings of the 3rd ACM SIGSPATIAL International Workshop on Location-Based Social Networks. 41-44. https://doi.org/10.1145/2063212.2063215

[13] Farber, S., \& Fu, L. (2017). Dynamic public transit accessibility using travel time cubes: Comparing the effects of infrastructure (dis) investments over time. Computers, Environment and Urban Systems. 62: 30-40. https://doi.org/10.1016/j.compen vurbsys.2016.10.005

[14] Saif, M. A., Zefreh, M. M., \& Torok, A. (2019). Public transport accessibility: a literature review. Periodica Polytechnica Transportation Engineering. 47(1): 36-43. https://doi.org/10.3311/pptr.12072

[15] Han, Y., Li, W., Wei, S., \& Zhang, T. (2018). Research on passenger's travel mode choice behavior waiting at bus station based on sem-logit integration model. Sustainability. 10(6): 1996. https://doi.org/10.3390/su10061996

[16] Chiu Chuen, O., Karim, M. R., \& Yusoff, S. (2014). Mode choice between private and public transport in Klang Valley, Malaysia. The Scientific World Journal, 2014. https://doi.org/10.1155/2014/394587

[17] Sterman, J.D. (2000), 'Business Dynamics: Systems Thinking and Modeling for a Complex World', McGraw-Hill, Boston. 
[18] Sumari, S., Ibrahim, R., Zakaria, N. H., \& Ab Hamid, A. H. (2013). Comparing three simulation model using taxonomy: System dynamic simulation, discrete event simulation, and agent-based simulation. International Journal of Management Excellence. 1(3): 54-59. https://doi.org/10.17722/ijme.v1i3.17

[19] Nurdden, A., Rahmat, R. A. O. K., \& Ismail, A. (2007). Effect of transportation policies on modal shift from private car to public transport in Malaysia. Journal of applied Sciences. 7(7): 1013-1018. https://doi.org/10.3923/jas.2007.1013.1018

[20] Karim (2018). Evaluating Travel Demand Strategies to Mitigate Congestion Index in Kuala Lumpur Using an Integration Model of System Dynamics and Genetic Algorithm. Unpublished Master Thesis. Universiti Utara Malaysia.

[21] Wang, H., Zhang, K., Chen, J., Wang, Z., Li, G., \& Yang, Y. (2018). System dynamics model of taxi management in metropolises: Economic and environmental implications for Beijing. Journal of environmental management. 213: 555-565. https://doi.org/10. 1016/i.jenvman.2018.02.026

[22] Haraldsson, H. V. (2004). Introduction to system thinking and causal loop diagrams. Department of Chemical Engineering, Lund University. 3-4.

[23] Eugine Tafadzwa Maziriri, Miston Mapuranga, Justice Mushwana, Nkosivile Welcome Madinga. (2020). Antecedents That Influence the Intention to Use the Uber Mobile Application: Customer Perspectives in South Africa. International Journal of Interactive Mobile Technologies. 14(8): 76-96. https://doi.org/10.3991/ijim.v14i08. $\underline{10632}$

[24] Amaya Andri Damaini, Ginanjar Setyo Nugroho, Suyoto Suyoto. (2018). Fraud Crime Mitigation of Mobile Application Users for Online Transportation. International Journal of Interactive Mobile Technologies. 12(3): 153-167. https://doi.org/10. $\underline{\text { 3991/ijim.v12i3.8070 }}$

\section{Authors}

Muhamad Syafiq Abdul Ghani obtained his first degree in Islamic Finance and Banking from School of Business, Universiti Utara Malaysia, Sintok Kedah Malaysia. Currently he is studying his Master's Degree in Decision Science at Universiti Utara Malaysia. His research interest area focuses on the use of simulation approach applied in the transportation domain. Email: abdulghani4567@yandex.com

Norhaslinda Zainal Abidin is a Senior Lecturer at the Department of Decision Science, School of Quantitative Sciences, Universiti Utara Malaysia. She received her $\mathrm{PhD}$ on the Operational Research from the University of Salford, UK. Her main research interest is in the application of system dynamics simulation models to policy level issues such as in agriculture, health, transportation, manufacturing and public policy. Email: nhaslinda@uum.edu.my

Rosshairy Abdul Rahman, Ph.D is a senior lecturer at Decision Science Department, School of Quantitative Sciences, Universiti Utara Malaysia (UUM). She obtained her Ph.D in Decision Science/Operations Research, specifically in Metaheuristics. She is actively supervising Ph.D and Masters students in the area of operations research. She teach Heuristic and Research Methodology subject for postgraduate and undergraduate students. Dr. Rosshairy Abdul Rahman is a member of the Management Science and Operations Research Society of Malaysia (MSORSM) 
and Malaysian Mathematical Sciences Society (PERSAMA). Her intense research areas are in optimization, meta-heuristics, evolutionary algorithm and multi-criteria decision analysis in various domain especially agriculture. Email: shairy@uum.edu.my

Antoni Wibowo obtained his first degree of Applied Mathematics in 1995 and master degree of Computer Science in 2000. In 2003, He awarded a Japanese Government Scholarship (Monbukagakusho) to attend Master and $\mathrm{PhD}$ programs at Systems and Information Engineering in University of Tsukuba-Japan. He completed the second master degree in 2006 and $\mathrm{PhD}$ degree in 2009, respectively. His $\mathrm{PhD}$ research focused on machine learning, operations research, multivariate statistical analysis and mathematical programming, especially in developing nonlinear robust regressions using statistical learning theory. He has worked from 1997 to 2010 as a researcher in the Agency for the Assessment and Application of Technology Indonesia. From April 2010- September 2014, he worked as a senior lecturer in the Department of Computer Science - Faculty of Computing, and a researcher in the Operation Business Intelligence (OBI) Research Group, Universiti Teknologi Malaysia (UTM)-Malaysia. From October 2014-October 2016, he was an Associate Professor at Department of Decision Sciences, School of Quantitative Sciences in Universiti Utara Malaysia (UUM). Dr. Eng. Wibowo is currently working at Binus Graduate Program (Master in Computer Science) in Bina Nusantara University-Indonesia as a Specialist Lecturer and continues his research activities in machine learning, optimization, operations research, multivariate data analysis, data mining, computational intelligence and artificial intelligence. Email: anwibowo@binus.edu

Azatuliffah Alwi is a lecturer at School of Quantitative Sciences, Universiti Utara Malaysia. She obtained her Master in Decision Science from Universiti Utara Malaysia. Her research interests in the recent years has focus on the management and evaluation of road traffic issues in the urban area. Email: azatuliffah@uum.edu.my

Article submitted 2020-12-19. Resubmitted 2021-01-23. Final acceptance 2021-01-25. Final version published as submitted by the authors. 